\title{
Prevalence of opioid dispensings and concurrent gastrointestinal medications in Quebec
}

\author{
Rachel E Williams PhD MS ${ }^{1}$, Nevzeta Bosnic BA², Carolyn T Sweeney MPH ${ }^{3}$, \\ Ashlee W Duncan PhD MS ${ }^{3}$, Kristen B Levine MSPH${ }^{4}$, Michael Brogan BA ${ }^{2}$, Suzanne F Cook PhD ${ }^{3}$
}

RE Williams, N Bosnic, CT Sweeney, et al. Prevalence of opioid dispensings and concurrent gastrointestinal medications in Quebec. Pain Res Manage 2008;13(5):395-400.

BACKGROUND: Opioids are frequently prescribed for moderate to severe pain. A side effect of opioid usage is the inhibition of gastrointestinal (GI) motility, known as opioid-induced bowel dysfunction $(\mathrm{OBD})$. OBD is typically treated prophylactically with laxatives and/or acid suppressants.

AIM: The present study describes the prevalence of outpatient opioid dispensing, opioid patient demographics, and concomitant dispensing of opioids and GI medications in the Quebec Public Prescription Drug Insurance Plan in 2005.

METHODS: Using a retrospective cohort design, opioid dispensings were identified using claims and reimbursement data. Laxative and acid suppressant dispensings were also identified. Concurrent use was defined as having at least one 'GI medication-exposed day' overlapping an 'opioid-exposed day'.

RESULTS: More than $11 \%$ of the drug plan population was dispensed an opioid in 2005, and dispensings increased with age. Approximately two-thirds of patients who received an opioid were given codeine. Approximately one-third of opioid patients were concomitantly dispensed a GI medication, yet only $2 \%$ were dispensed a laxative.

CONCLUSIONS: Although the GI side effects of opioids are well known, these side effects appear to increase with age and duration of opioid use. Opioid-related side effects, particularly OBD, should be effectively managed so as not to lead to the cessation of opioid therapy.

Key Words: Dispensings; Epidemiology; Laxative; Opioid; Prevalence; Upper GI medication

\section{Prévalence de l'utilisation concomitante d'opi- acés et de médicaments GI au Québec}

HISTORIQUE : On prescrit souvent des opiacés pour la douleur de modérée à sévère. L'un des effets secondaires des opiacés est l'inhibition de la motilité gastro-intestinale (GI), connue sous le nom de dysfonction intestinale induite par les opiacés (DIO). La DIO est en général traitée de manière prophylactique au moyen de laxatifs et/ou de suppresseurs de l'acidité

OBJECTIF : La présente étude décrit la prévalence des ordonnances d'opiacés chez les patients non hospitalisés, les caractéristiques démographiques des patients sous opiacés et l'emploi concomitant d'opiacés et de médicaments GI selon les données du régime public d'assurancemédicaments du Québec pour 2005.

MÉTHODE : À partir d'un modèle de cohorte rétrospective, on a recensé les opiacés servis à partir des données de réclamations et de remboursements. On a également recensé les laxatifs et les suppresseurs de l'acidité servis. L'utilisation concomitante était définie par l'emploi le même jour d'au moins un médicament GI et d'un opiacé.

RÉSULTATS : Plus de $11 \%$ de la population qui bénéficie du régime d'assurance-médicaments a reçu une ordonnance d'opiacés en 2005 et la proportion augmentait avec l'âge. Il s'agissait de codéine chez près des deux tiers des patients sous opiacés. Environ un tiers des patients sous opiacés prenait concomitamment un médicament GI et pourtant, 2 \% seulement ont reçu un laxatif.

CONCLUSION : Bien que les effets secondaires GI des opiacés soient bien connus, ils semblent plus prévalents avec l'âge et la durée du traitement opiacé. Il faut traiter efficacement les effets secondaires liés aux opiacés, particulièrement la DIO, pour ne pas entraîner l'arrêt du traitement par opiacé.
$\mathrm{O}$ pioids are common treatments for patients with moderate to severe pain (1-3); however, pain management can be compromised by the adverse effects of opioid treatment, including inhibition of gastrointestinal (GI) motility (4-6). Opiates induce a delay in gastric emptying, which may lead to nausea and vomiting, and also slow intestinal and colonic transit, which may lead to constipation (7-11). Taken together, these inhibitory effects on GI motility are termed opioid-induced bowel dysfunction (OBD) and represent an important, and often dose-limiting, side-effect profile of opioid treatment.

Although large, population-based, prospective studies of OBD are lacking, estimates of the prevalence of opioidinduced constipation range from approximately $15 \%$ to $50 \%$ in nonmalignant pain patients $(12,13)$ and $25 \%$ to $90 \%$ in cancer patients $(14,15)$. Patients with continuing opioid therapy do not develop a tolerance to constipation, such as they may for

\footnotetext{
${ }^{1}$ Worldwide Epidemiology, GlaxoSmithKline, Collegeville, Pennsylvania, USA; ${ }^{2}$ Brogan Inc, Ottawa, Ontario; ${ }^{3}$ Worldwide Epidemiology, GlaxoSmithKline, Research Triangle Park; ${ }^{4}$ Department of Epidemiology, University of North Carolina at Chapel Hill, Chapel Hill, North Carolina, USA

Correspondence: Dr Rachel E Williams, GlaxoSmithKline, 12505 Collegeville Road, PO Box 5089, UP4305, Collegeville, Pensnsylvania 19426-0989, USA. Telephone 610-917-6534, fax 610-917-4818, e-mail rachel.e.williams@gsk.com
} 
other opioid-induced side effects such as nausea and vomiting $(16,17)$. In an attempt to avoid constipation, patients may reduce their opioid level or frequency of use, or they may discontinue opioid therapy altogether. Hence, in an effort to reduce constipation, effective pain management may be compromised $(2,18)$.

Prophylactic treatment for the constipating aspects of OBD is often recommended at the start of opioid therapy, especially in patients who need to use opioids chronically, such as terminally ill cancer patients $(14,19)$. Treatment of constipation typically includes laxatives and/or stool softeners; however, these therapies are often insufficient, and higher or more frequent doses may be required as the duration of opioid use increases $(20,21)$. Constipation and its sequelae may significantly reduce a patient's quality of life, lead to increased medical costs or lead to termination of needed pain medications.

Despite widespread recognition of OBD, the epidemiology of concomitant opioid use with laxatives or medications affecting the upper GI tract is poorly described. The objectives of our study were to describe the prevalence of outpatient opioid dispensing in the Quebec Public Prescription Drug Insurance Plan in 2005; describe the age and sex of the patients receiving opioids; gain a better understanding of the population that has chronic and long-term chronic opioid dispensings; assess the type of opioids being dispensed; and evaluate the concomitant dispensing of over-the-counter and prescription laxatives and/or upper GI medications in opioid users.

\section{METHODS}

\section{Quebec Public Prescription Drug Insurance Plan}

There are approximately eight million people residing in Quebec, Canada's second most populous province. This accounts for over $23 \%$ of the Canadian population. The source population for the present analysis includes enrollees covered under the Quebec Public Prescription Drug Insurance Plan. This program is set up to provide services for citizens who do not have private group insurance and is administered by La Régie de l'assurance maladie du Québec. All residents of Quebec, regardless of their financial situation, are eligible for enrollment in this government-based, universal health care plan; however, the plan is intended to enroll the following groups: those without a private health care plan; children of people covered by this public plan; people 65 years of age and older; and welfare recipients. In total, this drug prescription plan covers approximately 3.2 million of the eight million residents of the province.

The formulary for the Quebec Public Prescription Drug Insurance Plan registers more than 4500 over-the-counter and prescription drugs. Because the majority of the population in Quebec uses the public plan to obtain medications, this cohort can be considered generally representative of the larger Quebec population, excluding those residents with private insurance.

\section{Study population}

The present study design is a retrospective cohort design, with the analyses conducted at the personal level, using people as the unit of measurement. The study period was defined as January 1, 2005 to December 31, 2005. The inclusion criteria were designed to enroll adults with a full year of coverage in the Quebec Public Prescription Drug Insurance Plan. These criteria included people in the Quebec Public Prescription Drug Insurance Plan who were 18 years of age or older at the start of the study period; eligible for drug benefits for the entire study period; did not die before the end of the study period; and had at least one opioid dispensing between January 1, 2005, and December 31, 2005. Once all eligible patients were identified using the inclusion and exclusion criteria, a random sample of $25 \%$ of the patients was received, as per government guidelines.

\section{Opioid dispensings}

Opioid dispensings were identified by examining the claims data for opioids that were reimbursed by the Quebec Public Prescription Drug Insurance Plan. Opioids administered orally, by transdermal patch, rectal suppository and nasal spray were included. This included butorphanol tartrate, codeine (codeine phosphate, codeine phosphate with acetaminophen, codeine with codeine sulfate), fentanyl, hydromorphone $\mathrm{HCl}$, meperidine $\mathrm{HCl}$, morphine (morphine $\mathrm{HCl}$, morphine sulfate), oxycodone (oxycodone $\mathrm{HCl}$, oxycodone with acetaminophen), pentazocine and sufentanil citrate.

Due to the nature of the data, all opioid dispensings were to outpatients; data on use of opioids by hospital inpatients were not available in the present study. It is understood that the data reflect no particular legal restriction on the units of opioid medication that may be dispensed. Physicians may prescribe more frequent, shorter-term dispensings rather than less frequent, longer-term dispensings. The data available for each dispensing were as follows: drug name, date of dispensing, number of days supplied, number of units dispensed and strength of units dispensed. To determine the specific days of intended opioid use, the date of dispensing was identified and the number of days supplied for each opioid dispensing. From this information, 'opioid-exposed days' were defined as all dates beginning with the date of dispensing through the end of the number of days supplied.

\section{Chronic use definitions}

'Chronic opioid use' was defined a priori as 60 or more consecutive opioid-exposed days, with no more than seven consecutive days between the end of one dispensing and the start of the next dispensing. This gap in opioid-exposed days was allowed because patients do not always get their prescriptions filled on time and opioid use maybe adjusted to meet their pain needs, making an opioid prescription last longer than prescribed. From this definition, 'chronic users' were defined as people with at least one period of chronic opioid use in 2005.

A subset of the chronic users, 'long-term chronic users' were also defined a priori; these people met the definition of a chronic user and had at least 180 consecutive opioid-exposed days, with no more than seven consecutive days between the end of one dispensing and the start of the next dispensing.

'Nonchronic users' were defined a priori as people with an opioid dispensing that did not meet the definition for chronic use during the study period. Hence, nonchronic users had 59 or fewer consecutive opioid-exposed days. Having seven days or less between opioid dispensings was considered consecutive as described above; eight or more days between opioid dispensings was considered a new period of use, and hence, not consecutive.

During the course of the one-year study period, a person may have periods of chronic opioid use and other periods of nonchronic opioid use. For these analyses, people with any chronic opioid use during the study period were considered chronic users for all analyses. A person was considered a 
nonchronic user if all opioid dispensings were nonchronic (59 or fewer consecutive opioid-exposed days). Furthermore, a person with any chronic opioid use did not meet the study definition of a nonchronic user in 2005. This decision ensured mutually exclusive groups, allowed comparisons between people with and without any chronic opioid use and aided in the understanding of study results.

\section{Concurrent laxative and/or acid suppressants}

All dispensings of over-the-counter and prescription laxatives and agents that reduce gastric acid secretion were identified in the study population. Laxatives included bulk laxatives (plantago seed, psyllium hydrophilic muciloid), emollient laxatives (docusate calcium, docusate sodium, mineral oil), osmotic laxatives (glycerin, lactulose, magnesium hydroxide, sodium citrate with sodium lauryl sulfoacetate, sodium phosphate monobasic with sodium phosphate dibasic, and carbowax with sodium sulfate, sodium bicarbonate, sodium chloride and potassium chloride) and stimulant laxatives (bisacodyl, cascara sagrada, cascara sagrada with magnesium hydroxide, sennosides, sennosides with docusate sodium). Acid suppressants included proton pump inhibitors (esomeprazole magnesium trihydrate, lansoprazole, omeprazole magnesium, pantoprazole, rabeprazole sodium) and histamine $\mathrm{H}_{2}$ receptor antagonists (cimetidine, cimetidine hydrochloride, famotidine, nizatidine, ranitidine $\mathrm{HCl}$ ). Antacids and absorbents were not included in the present study because they may be used in the population for reasons unrelated to a GI symptom (ie, antacids as a calcium supplement).

'Laxative-exposed days' and 'acid suppressant-exposed days' were calculated with the same methodology used for 'opioidexposed days.' These periods included the number of days between the dispensing date of the laxative and/or acid suppressant through the last day supplied for each agent. Use of concurrent laxative medication was defined as having at least one laxative-exposed day that overlapped with an opioidexposed day. Use of concurrent acid suppressants was defined as having at least one acid suppressant-exposed day that overlapped with an opioid-exposed day.

\section{Analyses}

Descriptive analyses were conducted to meet each of the objectives. The prevalence of opioid use was defined as the number of patients in the Quebec Public Prescription Drug Insurance Plan database with at least one opioid dispensing divided by the number of eligible patients enrolled in the prescription drug plan, according to the study inclusion criteria.

All remaining analyses focused on the population of interest - people with at least one opioid dispensing during 2005. Using this study population as the denominator, sex, age, chronicity of use, type of opioid used, and concurrent use of laxatives and/or acid suppressants were described. Data from the Quebec Public Prescription Drug Insurance Plan were analyzed using SAS version 9.1 (SAS Institute Inc, USA).

\section{RESULTS}

\section{Prevalence of opioid use in Quebec}

In the random sample of $25 \%$ of all eligible patients, $11.3 \%$ of the population in the Quebec Public Prescription Drug Insurance Plan were dispensed an opioid in 2005. Based on an estimated 2,670,338 people in the eligible population, this proportion $(11.3 \%)$ may be extrapolated to an estimated 300,660 people in Quebec who were dispensed an opioid in

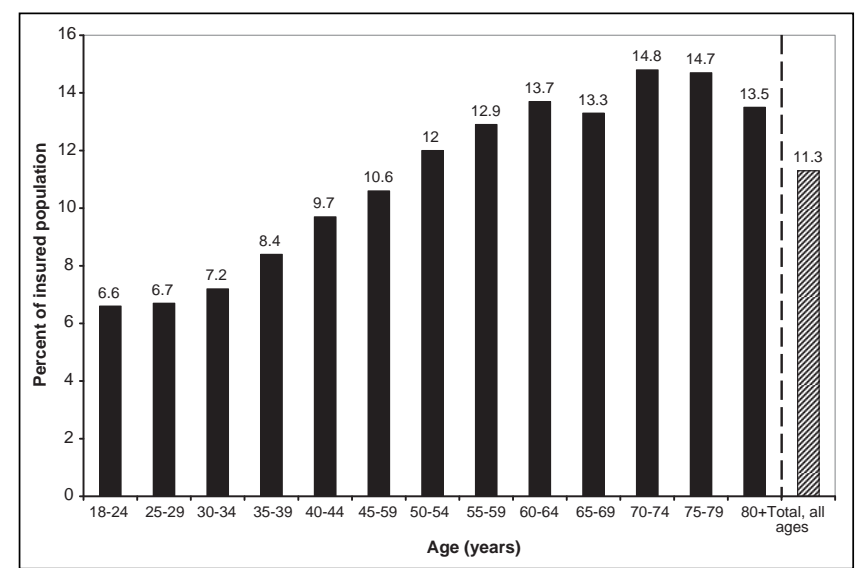

Figure 1) Prevalence of opioid use in Quebec in 2005 using the Quebec Public Prescription Drug Insurance Plan database

2005. In the general population, a greater proportion of women $(12.6 \%)$ were dispensed opioids than men $(9.6 \%)$. The use of opioids increased with age in both sexes until approximately 80 years of age (Figure 1). Peak prevalence of use $(14.8 \%)$ occurred in the 70 - to 74-year-old group.

\section{Characteristics of people with opioid dispensings}

Of the 75,165 people in the study population who had received an opioid dispensing, $61.0 \%$ were women $(n=45,888)$ and $39.0 \%$ were men $(n=29,277)$ (Table 1$)$. Most patients receiving an opioid were given codeine $(65.7 \%)$, followed by hydromorphone $\mathrm{HCl}(25.0 \%)$, oxycodone $(11.4 \%)$ and morphine $(8.1 \%)$. The same pattern and similar percentages were found between men and women.

\section{Chronic opioid use}

Three categories of patients were defined a priori based on their opioid dispensings: chronic opioid users, long-term chronic opioid users and nonchronic opioid users. Using these categories, $12.4 \%$ of patients who received opioids were chronic users and $87.6 \%$ were nonchronic users (Table 1). Furthermore, a similar percentage of men and women were chronic $(12.2 \%$ and $12.5 \%$, respectively) and nonchronic users $(87.8 \%$ and $87.5 \%$, respectively). Approximately onehalf of the chronic users $(6.4 \%$ of the $12.4 \%)$ were long-term chronic users; the percentage of men and women in this category was similar (6.5\% and $6.3 \%$, respectively).

The type of opioid prescribed differed among nonchronic, chronic and long-term chronic users (Table 2). Codeine was dispensed to $69.6 \%$ of nonchronic users, followed by hydromorphone $\mathrm{HCl}$ (23.3\%); all other types of opioids were dispensed to less than $10 \%$ of nonchronic users. Among chronic users, codeine was dispensed to $38.4 \%$, followed closely by hydromorphone $\mathrm{HCl}(37.1 \%)$, oxycodone $(27.2 \%)$, fentanyl (22.3\%) and morphine (16.2\%). In long-term chronic opioid users, percentages were similar to those in chronic users, although codeine was dispensed less frequently (29.9\%) and methadone was dispensed more frequently $(11.7 \%)$.

\section{Concurrent laxative and/or acid suppressants}

Approximately one-third of people (30.5\%) with an opioid dispensing were concomitantly dispensed a laxative or acid suppressant medication. Furthermore, slightly more women 
TABLE 1

Characteristics of the study population of people in the Quebec Public Prescription Drug Insurance Plan with an opioid dispensed in 2005

\begin{tabular}{|c|c|c|c|}
\hline & $\begin{array}{c}\text { Men } \\
(\mathrm{n}=29,277) \\
\mathrm{n}(\%)\end{array}$ & $\begin{array}{c}\text { Women } \\
(n=45,888) \\
n(\%)\end{array}$ & $\begin{array}{c}\text { Total } \\
(\mathrm{n}=75,165) \\
\mathrm{n}(\%)\end{array}$ \\
\hline \multicolumn{4}{|l|}{ Age, years* } \\
\hline $18-24$ & $890(3.0)$ & $2680(5.8)$ & $3570(4.7)$ \\
\hline $25-29$ & $937(3.2)$ & $2216(4.8)$ & $3153(4.2)$ \\
\hline $30-34$ & $1162(4.0)$ & $2015(4.4)$ & $3177(4.2)$ \\
\hline $35-39$ & $1553(5.3)$ & $2256(4.9)$ & $3809(5.1)$ \\
\hline $40-44$ & $2097(7.2)$ & $2863(6.2)$ & $4960(6.6)$ \\
\hline $45-49$ & $2351(8.0)$ & $2833(6.2)$ & $5184(6.9)$ \\
\hline $50-54$ & $2261(7.7)$ & $3110(6.8)$ & $5371(7.1)$ \\
\hline $55-59$ & $2524(8.6)$ & $3629(7.9)$ & $6153(8.2)$ \\
\hline $60-64$ & $2731(9.3)$ & $4360(9.5)$ & $7091(9.4)$ \\
\hline $65-69$ & $3983(13.6)$ & $4997(10.9)$ & 8980 (11.9) \\
\hline $70-74$ & $3868(13.2)$ & $5122(11.2)$ & $8990(12.0)$ \\
\hline $75-79$ & $2739(9.4)$ & $4503(9.8)$ & $7242(9.6)$ \\
\hline$\geq 80$ & $2181(7.4)$ & $5304(11.6)$ & $7485(10.0)$ \\
\hline \multicolumn{4}{|l|}{ Chronicity of use } \\
\hline Nonchronic, $<60$ days & $25,709(87.8)$ & $40,142(87.5)$ & $65,851(87.6)$ \\
\hline Chronic, $\geq 60$ days & $3568(12.2)$ & $5746(12.5)$ & $9314(12.4)$ \\
\hline $\begin{array}{l}\text { Long-term chronic, } \\
\geq 180 \text { days }\end{array}$ & $1911(6.5)$ & $2876(6.3)$ & $4787(6.4)$ \\
\hline \multicolumn{4}{|l|}{ Type of opioid } \\
\hline Codeine & $18,961(64.8)$ & $30,455(66.4)$ & $49,416(65.7)$ \\
\hline Hydromorphone $\mathrm{HCl}$ & $7853(26.8)$ & $10,939(23.8)$ & $18,792(25.0)$ \\
\hline Oxycodone & $3317(11.3)$ & $5242(11.4)$ & $8559(11.4)$ \\
\hline Morphine & $2300(7.9)$ & $3756(8.2)$ & $6056(8.1)$ \\
\hline Fentanyl & $898(3.1)$ & $1890(4.1)$ & $2788(3.7)$ \\
\hline Meperidine $\mathrm{HCl}$ & $839(2.9)$ & $1728(3.8)$ & $2567(3.4)$ \\
\hline Methadone & $451(1.5)$ & $310(0.7)$ & $761(1.0)$ \\
\hline Pentazocine & $55(0.2)$ & $135(0.3)$ & $190(0.3)$ \\
\hline Butorphanol tartrate & $<6(<0.1)^{\dagger}$ & $19(<0.1)$ & $<6(<0.1)^{\dagger}$ \\
\hline Sufentanil citrate & $0(0.0)$ & $<6(<0.1)^{\dagger}$ & $<6(<0.1)^{\dagger}$ \\
\hline
\end{tabular}

${ }^{*}$ Age at January 1, 2005; ${ }^{\dagger}$ When a data entry is between 1 and 5 patients, the exact number is not provided to ensure patient confidentiality; therefore, the data are reported as $<6$

(31.9\%) than men $(28.3 \%)$ received a concurrent dispensing of opioids, and a laxative or acid suppressant (Table 3). When patients were examined by age group, a substantial difference in concomitant dispensings of opioids and a laxative or acid suppressant was observed; $23.5 \%$ of patients younger than 65 years of age were concurrently dispensed an opioid and a laxative or acid suppressant medication compared with 39.5\% of patients 65 years of age and older. The dispensing of concomitant laxative or acid suppressant medications increased as patients were dispensed opioids for extended periods of time; concurrent dispensings of laxative or acid suppressant medications was observed in $26.1 \%$ of nonchronic opioid users, $59.9 \%$ of chronic users and $62.7 \%$ of long-term chronic users.

Slightly more than $2 \%$ of people with an opioid dispensing had a laxative dispensed concurrently (Table 3 ), and the percentage of men and women in this category was similar $(2.4 \%$ and $1.9 \%$, respectively). There were more emollient laxatives $(1.8 \%)$ and stimulants $(1.5 \%)$ concomitantly dispensed with an opioid than osmotic laxatives $(0.4 \%)$. Furthermore, people
TABLE 2

Type of opioid dispensed among participants of the Quebec Public Prescription Drug Insurance Plan, stratified by type of opioid user in 2005

\begin{tabular}{lccc}
\hline & $\begin{array}{c}\text { Nonchronic } \\
(\mathbf{n = 6 5 , 8 5 1 )} \\
\%\end{array}$ & $\begin{array}{c}\text { Chronic } \\
(\mathbf{n}=9314) \\
\%\end{array}$ & $\begin{array}{c}\text { Long-term } \\
\text { chronic } \\
\text { (n=4787) } \\
\%\end{array}$ \\
\hline Cype of opioid & 69.6 & 38.4 & 29.9 \\
Hydromorphone HCl & 23.3 & 37.1 & 35.3 \\
Oxycodone & 9.2 & 27.2 & 27.7 \\
Morphine & 6.9 & 16.2 & 17.1 \\
Fentanyl & 1.1 & 22.3 & 24.0 \\
Meperidine HCl & 3.4 & 3.6 & 2.9 \\
Methadone & 0.1 & 7.3 & 11.7 \\
Pentazocine & 0.2 & 0.6 & 0.8 \\
Butorphanol tartrate & $<0.1^{*}$ & $<0.1^{*}$ & $<0.1^{*}$ \\
Sufentanil citrate & 0.0 & $<0.1^{*}$ & $<0.1^{*}$ \\
\hline
\end{tabular}

*The exact numbers between 1 and 5 are not presented in a data entry to protect patient confidentiality; therefore, the data are reported as $<0.1 \%$

65 years of age or older had slightly more concomitant opioid and laxative dispensings than those younger than 65 years of age $(2.6 \%$ versus $1.8 \%)$. More concomitant laxatives were dispensed among chronic users $(11.3 \%)$ and long-term chronic users $(15.2 \%)$ than nonchronic users $(0.8 \%)$. The nonchronic users may serve as a surrogate upper bound for patients not prescribed opioids; therefore, the dispensing of laxatives in patients who are also dispensed opioids can be assumed to be at least 10 -fold greater than nonopioid users. Among the longterm chronic users, slightly more women $(16.8 \%)$ than men (12.7\%) had concomitant laxative dispensings, and almost all of the laxatives used were dispensed over the counter.

Nearly one-third (29.8\%) of patients with an opioid dispensing had a concurrent acid suppressant dispensed (Table 3 ), and more women than men received a concurrent dispensing of opioids and acid suppressants $(31.2 \%$ and $27.6 \%$, respectively). Twice as many chronic (56.6\%) and long-term $(58.5 \%)$ opioid users had concomitant acid suppressant treatments dispensed when compared with nonchronic opioid users (25.7\%). Assuming nonchronic users constitute an upper bound for nonopioid users, those with chronic opioid dispensings were dispensed acid suppressants at least twice as often as those with nonchronic opioid dispensings.

\section{DISCUSSION}

The results of the present study confirm that a substantial proportion of patients in the Quebec Public Prescription Drug Insurance Plan received an opioid dispensing in 2005. Additionally, the proportion of subjects who were dispensed opioids increased with age, and many of the patients were concurrently dispensed a laxative or acid suppressant medication.

Interestingly, approximately two-thirds of patients dispensed an opioid received codeine. In comparison, a Canadian survey on chronic pain and prevalence of opioid use found that $16.9 \%(n=340)$ of 2012 respondents were taking prescription analgesic medication. Among individuals surveyed with chronic pain who were taking a prescription analgesic medication $(n=340), 22.6 \%(n=77)$ used an opioid and $67.5 \%(n=52)$ of the opioid users reported taking codeine (22). Hence, the data in the Quebec plan and the survey of chronic pain 
TABLE 3

Concurrent dispensings of laxative and/or acid suppressant therapies with opioids by sex in the Quebec Public Prescription Drug Insurance Plan in 2005

\begin{tabular}{|c|c|c|c|c|c|c|c|c|}
\hline & $\begin{array}{c}\text { Men } \\
(n=29,277) \\
\%\end{array}$ & $\begin{array}{c}\text { Women } \\
(\mathrm{n}=45,888) \\
\%\end{array}$ & $\begin{array}{c}<65 \text { years old } \\
(n=42,468) \\
\%\end{array}$ & $\begin{array}{c}\geq 65 \text { years old } \\
(n=32,697) \\
\%\end{array}$ & $\begin{array}{c}\text { Nonchronic } \\
(\mathrm{n}=65,851) \\
\%\end{array}$ & $\begin{array}{c}\text { Chronic } \\
(\mathrm{n}=9314) \\
\%\end{array}$ & $\begin{array}{c}\text { Long-term chronic } \\
(\mathrm{n}=4787) \\
\%\end{array}$ & $\begin{array}{c}\text { Total } \\
(\mathrm{n}=75,165) \\
\%\end{array}$ \\
\hline Laxatives & 1.9 & 2.4 & 1.8 & 2.6 & 0.8 & 11.3 & 15.2 & 2.2 \\
\hline OTC & 1.9 & 2.3 & 1.8 & 2.6 & 0.8 & 11.2 & 14.9 & 2.2 \\
\hline Prescription & $<0.1^{*}$ & $<0.1^{*}$ & $<0.1^{*}$ & $<0.1^{*}$ & $<0.1^{*}$ & $<0.1^{*}$ & $<0.1^{*}$ & $<0.1^{*}$ \\
\hline Acid suppressant therapies & 27.6 & 31.2 & 23.0 & 38.7 & 25.7 & 56.6 & 58.5 & 29.8 \\
\hline OTC & $<0.1^{*}$ & $<0.1^{*}$ & 0.0 & $<0.1^{*}$ & $<0.1^{*}$ & $<0.1^{*}$ & 0.0 & $<0.1^{*}$ \\
\hline Prescription & 27.6 & 31.2 & 23.0 & 38.7 & 25.7 & 56.6 & 58.5 & 29.8 \\
\hline $\begin{array}{l}\text { Laxatives or acid } \\
\text { suppressant therapies }{ }^{\dagger}\end{array}$ & 28.3 & 31.9 & 23.5 & 39.5 & 26.1 & 59.9 & 62.7 & 30.5 \\
\hline
\end{tabular}

${ }^{*}$ The exact numbers between 1 and 5 in a data entry are not presented to protect patient confidentiality; therefore, the data are presented as <0.1\%; ${ }^{\dagger}$ All types of laxative. Acid suppressant therapies include proton pump inhibitors and histamine $\mathrm{H}_{2}$ receptor antagonists. OTC Over-the-counter

patients found similar results, with approximately two-thirds of opioid users taking codeine.

Also, although $30.5 \%$ of people who were dispensed an opioid were also dispensed a laxative or acid suppressant, only $2.2 \%$ were dispensed a laxative concomitantly. This may be due in part to underuse of laxatives for opioid-induced constipation, and/or the way laxatives are reimbursed in this system. The constipating effects of opioid are well known (12-15); hence, treatment is important to not compromise pain management. One study showed that $41 \%$ of patients receiving a mean dose of morphine $83 \mathrm{mg} /$ day reported constipation as a side effect even though they were taking a bowel regimen (23).

Also, the reimbursement for laxatives differs by drug plans; hence, some patients may pay out-of-pocket for laxatives that do not show up in the drug plan data. Further investigation into the cost per laxative claim revealed that five of the top 10 most frequently prescribed laxatives in the Ontario Drug Benefit Plan have an average cost per claim reimbursement of more than $\$ 12$. Conversely, only one of the 10 most frequently prescribed laxatives in the Quebec Public Prescription Drug Insurance Plan has a cost per claim reimbursement of approximately $\$ 12$; nearly $80 \%$ of the 10 most frequently prescribed laxatives in the Quebec plan have an average cost or claim reimbursement of $\$ 2$. Therefore, differences between over-thecounter laxative information obtained from various health plans in Canada may be partially due to differences in filing for reimbursement rather than true differences in the use between the populations.

The gastrointestinal side effects of opioids are well known, and the present study illustrates that these side effects may increase with age and duration of opioid use. As anticipated, the chronic and long-term chronic opioid users had greater concomitant dispensing of GI medications than nonchronic users; laxatives were dispensed at least 10 times more frequently and acid suppressants at least twice as frequently in chronic opioid users than nonchronic opioid users. We believe the nonchronic users may represent an upper bound for the nonopioid users. Because the older population is more likely to have comorbidities and reduced GI functioning, any potential opioid-related side effects may have a greater impact. Therefore, greater focus on pain management and appropriate treatment of associated side effects may be especially important for this population because it is critical that opioid-induced side effects do not lead to cessation of the necessary opioid therapy.

There are several limitations of the present study due to the use of a prescription drug plan database. Although we have actual dispensings of medications, we do not have prescriptions or patient-reported data. Therefore, we cannot account for possible differences between the dispensing data and the instructions given by the physician, or the actual medication use by the patient. When opioids are prescribed on an as-needed basis, the pharmacist has to make the assumption that the number of units per day divided by total number of units equals the number of days supplied; therefore, the number of days supplied may be an underestimate or overestimate of the actual number of days a medication was used. We also do not know if the concomitant GI medications were prescribed due to side effects of the opioid or for other reasons. Considering the large differences between chronic and nonchronic opioid users in both concurrent laxative and acid suppressant use, it is likely that these GI treatments were in response to opioid-related side effects.

Despite these limitations, there are several strengths to this database analysis study. This drug plan is likely representative of approximately 3.2 million residents of Quebec. All drug dispensings must be prescribed by a physician, even if the medications can be bought over the counter. Drugs are identified by the Canadian Drug Identification Number, which signifies a unique combination of chemical entity, trade name, strength and form. Unlike insurance claims data in the United States, the database used in the present study contains information on over-the-counter medications, which is essential when evaluating laxative and acid suppressant use. Lastly, due to the large sample size available, we were able to identify concomitant medications that were used in only a small percentage of the population.

\section{CONCLUSION}

Opioids represent a frequently dispensed medication. Associated with their use is an increase in concomitant medications to treat OBD; in particular, laxatives and acid suppressant therapies. The use of these medications is essential because, for some patients, cessation of opioid therapy has negative and dramatic consequences due to the requirement of analgesia to relieve their pain. 
STATEMENT OF INTERESTS: REW and SFC are employees of GlaxoSmithKline and have stocks and shares in GlaxoSmithKline. CS was a contractor to GlaxoSmithKline and is currently an employee of RTI Health Solutions. AWD is a contractor to GlaxoSmithKline. NB and $\mathrm{MB}$ received funding from GlaxoSmithKline for access to data and data analyses. KBL received unrestricted educational grants from GlaxoSmithKline. The present study was funded by GlaxoSmithKline.

ACKNOWLEDGEMENTS: Work originated from Worldwide Epidemiology, GlaxoSmithKline, Research Triangle Park, North Carolina, USA.

\section{REFERENCES}

1. Inturrisi CE. Clinical pharmacology of opioids for pain. Clin J Pain 2002;18(4 Suppl):S3-13

2. Kalso E, Edwards JE, Moore RA, McQuay HJ. Opioids in chronic non-cancer pain: A systematic review of efficacy and safety. Pain 2004;112:372-80

3. Walsh TD. Oral morphine in chronic cancer pain. Pain 1984;18:1-11.

4. Bloodworth D. Issues in opioid management. Am J Phys Med Rehabil 2005;84(3 Suppl):S42-55

5. Cleary JF. The pharmacologic management of cancer pain. J Palliat Med 2007;10:1369-94

6. Trescot AM, Boswell MV, Atluri SL, et al. Opioid guidelines in the management of chronic non-cancer pain. Pain Physician 2006;9:1-39.

7. Murphy DB, Sutton JA, Prescott LF, Murphy MB. Opioid-induced delay in gastric emptying: A peripheral mechanism in humans. Anesthesiology 1997;87:765-70.

8. Yuan CS, Foss JF, O'Connor M, Roizen MF, Moss J. Effects of lowdose morphine on gastric emptying in healthy volunteers. J Clin Pharmacol 1998;38:1017-20.

9. Holzer P. Treatment of opioid-induced gut dysfunction. Expert Opin Investig Drugs 2007;16:181-94.
10. Mehendale SR, Yuan CS. Opioid-induced gastrointestinal dysfunction. Dig Dis 2006;24:105-12.

11. Panchal SJ, Müller-Schwefe P, Wurzelmann JI. Opioid-induced bowel dysfunction: prevalence, pathophysiology and burden. Int J Clin Pract 2007;61:1181-7.

12. Allan L, Hays H, Jensen NH, et al. Randomised crossover trial of transdermal fentanyl and sustained release oral morphine for treating chronic non-cancer pain. BMJ 2001;322:1154-8.

13. Moore RA, McQuay HJ. Prevalence of opioid adverse events in chronic non-malignant pain: Systematic review of randomised trials of oral opioids. Arthritis Res Ther 2005;7:R1046-51.

14. Meuser T, Pietruck C, Radbruch L, et al. Symptoms during cancer pain treatment following WHO guidelines: A longitudinal followup study of symptom prevalence, severity and etiology. Pain 2001;93:247-57.

15. Sykes NP. The relationship between opioid use and laxative use in terminally ill cancer patients. Palliat Med 1998;12:375-82.

16. Glare P, Walsh D, Sheehan D. The adverse effects of morphine: A prospective survey of common symptoms during repeated dosing for chronic cancer pain. Am J Hosp Palliat Care 2006;23:229-35.

17. Staats PS, Markowitz J, Schein J. Incidence of constipation associated with long-acting opioid therapy: A comparative study. South Med J 2004;97:129-34

18. Thorpe DM. Management of opioid-induced constipation. Curr Pain Headache Rep 2001;5:237-40.

19. McNicol E, Horowicz-Mehler N, Fisk RA, et al. Management of opioid side effects in cancer-related and chronic noncancer pain: A systematic review. J Pain 2003;4:231-56.

20. Pappagallo $M$. Incidence, prevalence, and management of opioid bowel dysfunction. Am J Surg 2001;182(5A Suppl):11S-8S.

21. Van Orden H. Constipation: An overview of treatment. J Pediatr Health Care 2004;18:320-2

22. Moulin DE, Clark AJ, Speechley M, Morley-Forster PK. Chronic pain in Canada - Prevalence, treatment, impact and the role of opioid analgesic. Pain Res Manage 2002;7:179-84.

23. Moulin DE, lezzi A, Amireh R, Sharpe WKJ, Boyd D, Merskey H. Randomized trial of morphine for chronic non-cancer pain. Lancet 1996;347:143-7. 


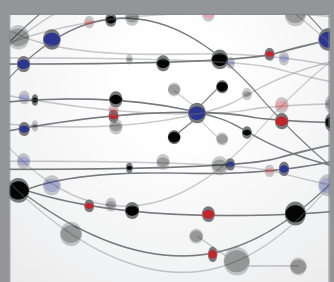

The Scientific World Journal
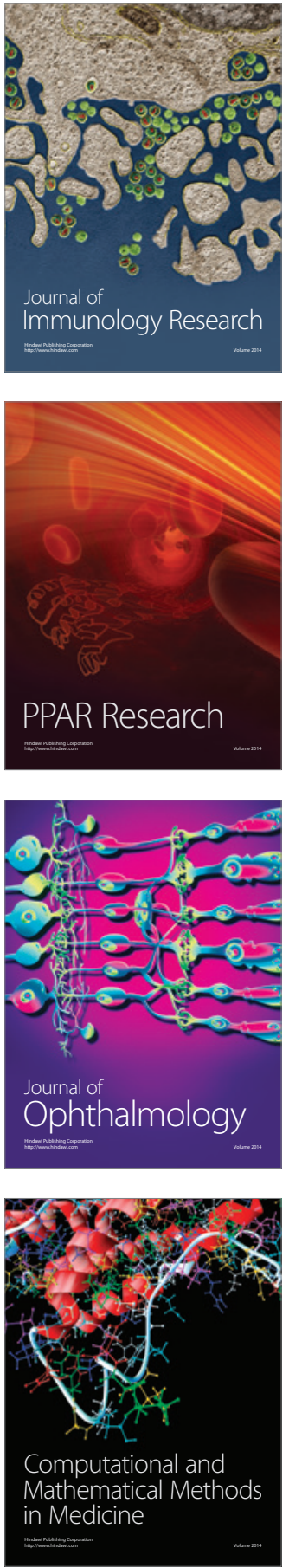

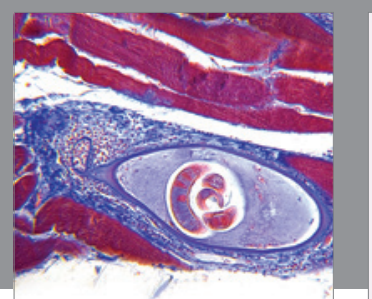

Gastroenterology Research and Practice

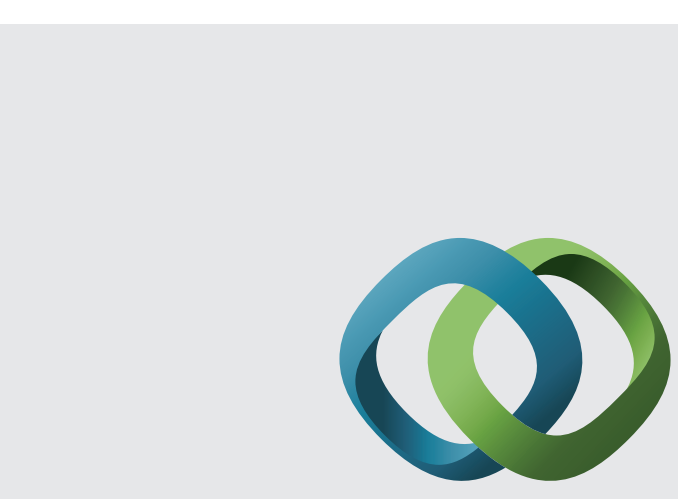

\section{Hindawi}

Submit your manuscripts at

http://www.hindawi.com
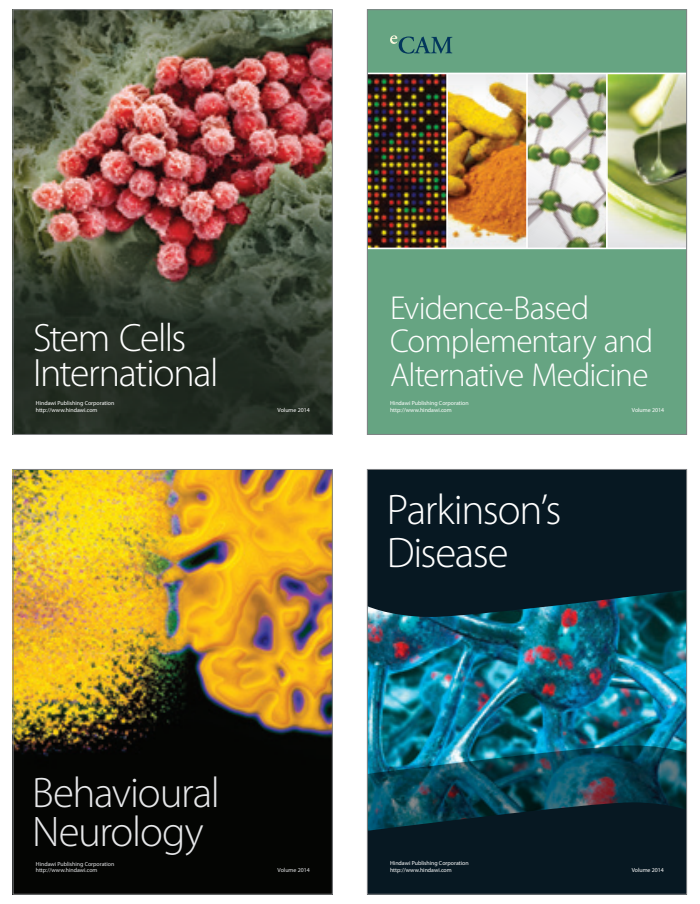
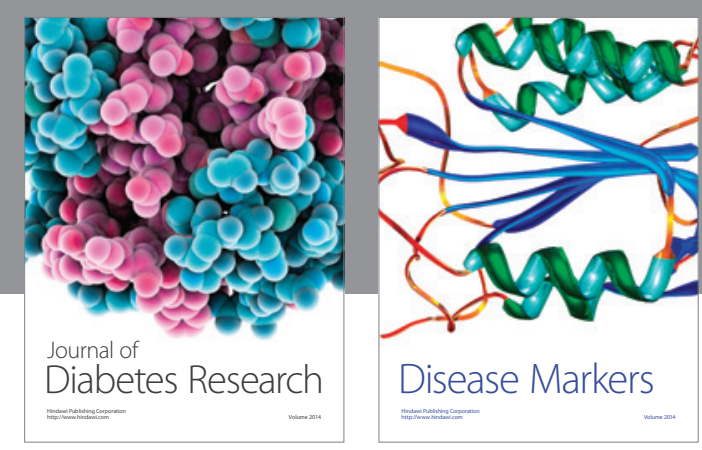

Disease Markers
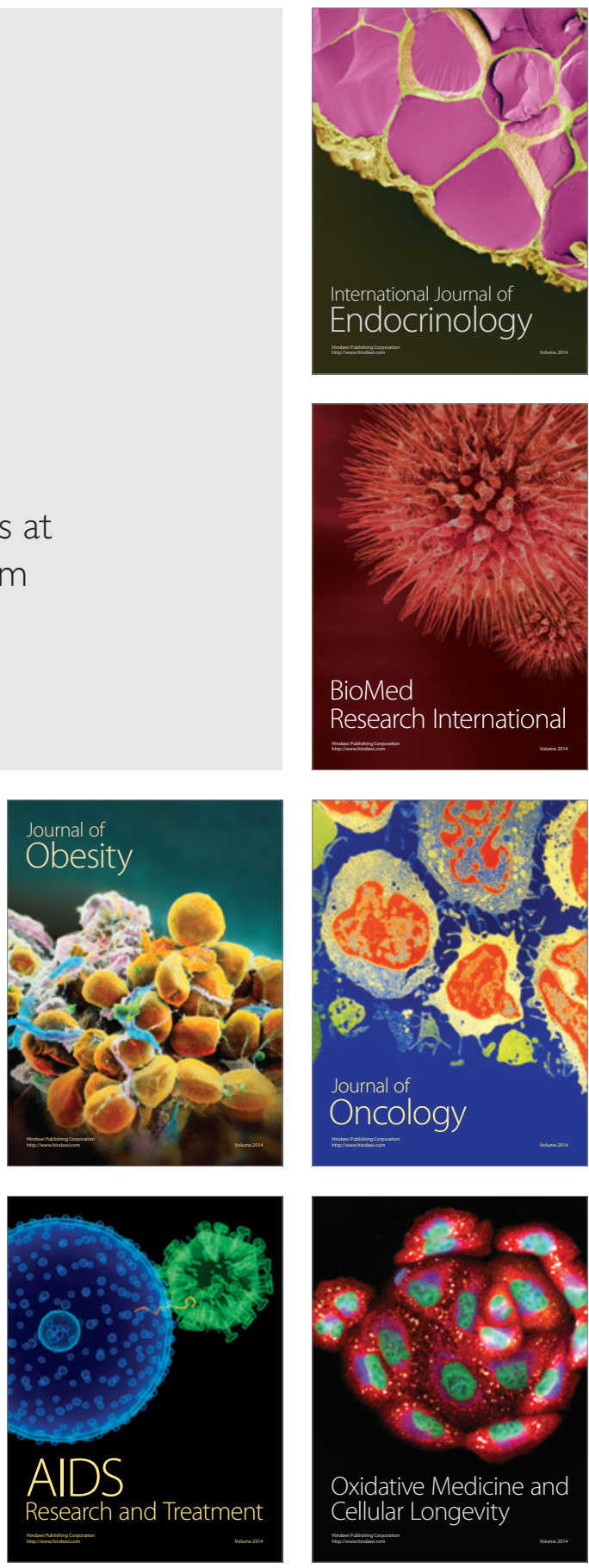